\section{References:}

1. Cohen IR. Chapter 1 - Introduction. In: Cohen IR, editor. Tending Adam's Garden. London: Academic Press; 2000. p. 3-6.

2.Chovatiya R, Medzhitov R. Stress, inflammation, and defense of homeostasis. Mol Cell. 2014;54(2):281-8. DOI: 10.1016/j.molcel.2014.03.030

3.Guzik TJ, Hoch NE, Brown KA, McCann LA, Rahman A, Dikalov $S$, et al. Role of the T cell in the genesis of angiotensin II induced hypertension and vascular dysfunction. J Exp Med. 2007;204(10):2449-60. DOl: 10.1084/jem.20070657

4.Caillon A, Paradis P, Schiffrin EL. Role of immune cells in hypertension. Br J Pharmacol. 2019;176(12):181828. DOI: 10.1111/bph.14427
5. Harrison DG, Coffman TM, Wilcox CS. Pathophysiology of Hypertension: The Mosaic Theory and Beyond. Circ Res. 2021;128(7):847-63. DOI: 10.1161/CIRCRESAHA.121.318082

6. McCarthy CG, Saha P, Golonka RM, Wenceslau CF, Joe B, Vijay-Kumar M. Innate Immune Cells and Hypertension: Neutrophils and Neutrophil Extracellular Traps (NETs). Compr Physiol. 2021;11(1):1575-89. DOI: 10.1002/cphy.c200020

7. Molinaro R, Yu M, Sausen G, Bichsel CA, Corbo C, Folco EJ, et al. Targeted delivery of Protein Arginine Deiminase-4 inhibitors to limit arterial intimal NETosis and preserve endothelial integrity. Cardiovasc Res. 2021. DOI: 10.1093/cvr/cvab074

\title{
COVID19 and Hypertension: Are We Facing a Syndemic?
}

\author{
NICOLAS F. RENNA, \\ Department of Pathology, Hospital Español de Mendoza, National University of \\ Cuyo, IMBECU-CONICET, \\ Mendoza, Argentina.
}

\section{DOI:10.30824/2106-4}

The term "syndemic" refers to synergistic health problems that affect the health of a population in its social and economic context. Coronavirus disease 2019 (COVID-19), indiced severe, acute respiratory syndrome Coronavirus 2 (SARSCoV-2), has become a global pandemic that is responsible for millions of deaths worldwide. High blood pressure is an important risk factor for cardiovascular disease and causes 7.5 million deaths per year (12.8\% of all deaths annually). The global burden of disease study suggests that systolic blood pressure is accountable for the highest proportion of premature death, with 212 million years lost ${ }^{1}$.

Early benign case series did not indicate an excess of hypertension in people admitted to hospital with COVID-192. Some later data showed a higher case fatality in patients with hypertension although not related for age ${ }^{3}$. New evidence from medical records in England, suggests that hypertension is not associated with hospital mortality from COVID -19 , hazard ratio (HR) 0.95, (95\% Cl 0.89-1.01). In sensitivity analyses, self-diagnosed hypertension

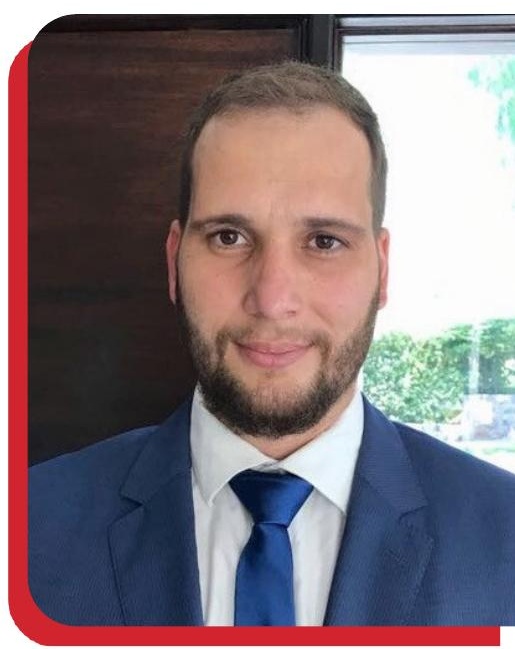

was associated with a slightly higher risk (HR 1.07, $95 \% \mathrm{Cl} 1.00-1.15)^{4}$.

Although some studies have concluded that hypertension could be a clinical predictor of severity ${ }^{5}$, the mechanism by which hypertension leads to an increased risk of COVID-19 is undoubtedly complex and may well be related to the underlying comorbidity. The prognosis for people with hypertension is markedly worse when COVID-19 infection is complicated by myocardial injury and in the presence of cardiovascular disease ${ }^{6}$. Target organ damage and cardiovascular events associated with poor blood pressure control increase with age. Therefore, it seems plausible that they may explain the observed associations between age, hypertension, and severity of COVID19 infection?.

\section{Are antihypertensive medications a serious risk of COVID-19 disease?}

From the beginning of the pandemic, many patients wondered whether they should 
discontinue these treatments, and inevitably some will have. The concern was fueled by the recognition that coronavirus 2 enters cells by binding to a component of the renin-angiotensin system, particularly ACE2. High-quality, large-scale, case-controlled, observational cohort studies reported that chronic treatment with ACEIs or ARBs was not associated with an increased risk of becoming infected with SARS-CoV-2, or of being hospitalized or dying from COVID-198. However, it is well known that observational studies have important limitations.

The advent of randomized clinical trials (RCT) was very important. Cohen J et al. ${ }^{9}$ report the first results of an RCT (the REPLACE COVID trial) examining the impact of continuing or withdrawing chronic ACEI or ARB treatment in 152 hospitalized COVID-19 patients at 20 international centers. This study showed that the results for patients previously treated with ACEls or ARBs and hospitalized for COVID-19 were similar, regardless of whether treatment with renin-angiotensin system inhibitors was continued or suspended during their hospital admission. Further reassurance comes from the fact that the conclusions of this REPLACE COVID trial are broadly consistent with the results of an RCT previously presented in the BRACE CORONA study. All hypertensive patients can be confident that continuing their current medications is safe and desirable ${ }^{10}$.

\section{Hypertension and COVID-19: What controversies remain?}

The relationship between blood pressure level and SARS-CoV-2 susceptibility or outcome in COVID-19 patients has not been sufficiently investigated, and the potential blood pressure target value in these patients is still unknown.

\section{The influence of blood pressure control on COVID-19:}

Determining the relationship between BP and COVID-19 outcome is not an easy task due to its high variability and dependence on comorbidities. Another point is chronic hypertension versus newonset hypertension in COVID-19: One of the main challenges in evaluating the relationship between hypertension and COVID-19 is the lack of data on the proportion of patients with hypertension before the hospitalization. The last controversy, is hypertension after COVID vaccination, although there is a single report of 9 cases of patients who presented post-vaccination hypertension, to date there is no reason for concern or for suspension of vaccination in hypertensive patients ${ }^{11}$.

This syndemic needs an immediate health response. Many countries will be facing the worst economic-health crisis in the last 3 centuries. We must seize this opportunity to learn and find solutions. Adequate knowledge and control of blood pressure, an outstanding debt, hand in hand with equal access to health, will surely help improve the health crisis.

\section{References:}

1.Forouzanfar $\mathrm{MH}$, Afshin A, Alexander LT, Anderson HR, Bhutta ZA, Biryukov S, et al. Global, regional, and national comparative risk assessment of 79 behavioral, environmental and occupational, and metabolic risks or clusters of risks, 1990-2015: a systematic analysis for the global burden of disease study 2015. Lancet. 2016;388(10053):1659-1724.

2.Huang C, Wang Y, Li X, Ren L, Zhao J, Hu Y, et al. Clinical features of patients infected with 2019 novel coronavirus in Wuhan, China. Lancet. 2020;395:497-506.

3.The Novel Coronavirus Pneumonia Emergency Response Epidemiology T. The epidemiological characteristics of an outbreak of 2019 novel coronavirus diseases (COVID-19) - China, 2020. China CDC Weekly. 2020;2:113-22

4.Williamson E, Walker AJ, Bhaskaran KJ, Bacon S, Bates C, Morton CE, et al. Factors associated with COVID-19-related death using OpenSAFELY. Nature 584: 430-43. DOI: 10.1038/s41586-020-2521-4

5.Lippi G, Wong J, Henry BM. Hypertension in patients with coronavirus disease 2019 (COVID-19): a pooled analysis. Pol Arch Intern Med. 2020;130:304-9.

6.Guo T, Fan Y, Chen M, Wu X, Zhang L, He T, et al. Cardiovascular implications of fatal outcomes of patients with coronavirus disease 2019 (COVID-19). JAMA Cardiol. 2020;5:811-18

7.Lewington S, Clarke R, Qizilbash N, Peto R, Collins R. Age-specific relevance of usual blood pressure to vascular mortality: a meta-analysis of individual data for one million adults in 61 prospective studies. Lancet. 2002;360:1903-13.

8.Williams B. Renin-angiotensin system inhibitors in hospitalised patients with COVID-19. Lancet Respir Med. 2021;9(3):221-222. doi:10.1016/ S2213-2600(21)00003-5 
9.Cohen JB, Hanff TC, William P, Sweitzer N, RosadoSantander NR, Medina C, Rodriguez-Mori JE, Renna N, Chang TI, Corrales-Medina V, AndradeVillanueva JF, Barbagelata A, Cristodulo-Cortez R, Díaz-Cucho OA, Spaak J, Alfonso CE, Valdivia-Vega R, Villavicencio-Carranza M, Ayala-García RJ, CastroCallirgos CA, González-Hernández LA, BernalesSalas EF, Coacalla-Guerra JC, Salinas-Herrera CD, Nicolosi L, Basconcel M, Byrd JB, Sharkoski T, Bendezú-Huasasquiche LE, Chittams J, Edmonston $D L$, Vasquez CR, Chirinos JA. Continuation versus discontinuation of renin-angiotensin system inhibitors in patients admitted to hospital with COVID-19: a prospective, randomised, open-label trial. Lancet Respir Med. 2021 Mar;9(3):275-284. doi: 10.1016/S2213-2600(20)30558-0

10.Lopes RD, Macedo AVS, de Barros E Silva PGM, Moll-Bernardes RJ, Feldman A, D’Andréa Saba Arruda
G, de Souza AS, de Albuquerque DC, Mazza L, Santos MF, Salvador NZ, Gibson CM, Granger CB, Alexander $J \mathrm{H}$, de Souza OF; BRACE CORONA investigators. Continuing versus suspending angiotensinconverting enzyme inhibitors and angiotensin receptor blockers: Impact on adverse outcomes in hospitalized patients with severe acute respiratory syndrome coronavirus 2 (SARS-CoV-2)--The BRACE CORONA Trial. Am Heart J. 2020 Aug;226:49-59. doi: 10.1016/j.ahj.2020.05.002.

11. Meylan S, Livio F, Foerster M, Genoud PJ, Marguet F, Wuerzner G; CHUV COVID Vaccination Center. Stage III Hypertension in Patients After mRNABased SARS-CoV-2 Vaccination. Hypertension. 2021 Jun;77(6):e56-e57.
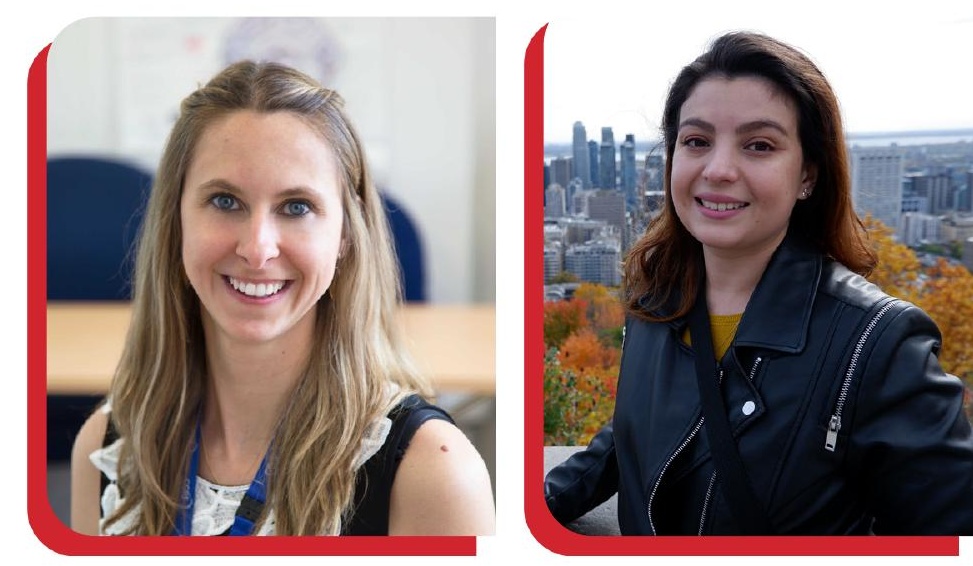

${ }^{2}$ School of Physical and Occupational Therapy, Faculty of Medicine, McGill University, Montreal, Canada.

DOI:10.30824/2106-5

Hypertensive disorders affect up to $10 \%$ of pregnancies worldwide, being a major health problem for women and their infants and causing increased maternal and infant morbidity and mortality.1, 2 The alarming global number of deaths caused by preeclampsia or due to cardiovascular morbidities following pregnancy with preeclampsia is a result of the current lack of knowledge about its causes and the limited therapies to handle maternal blood pressure (BP) during such insults or in the postpartum period. Improving the identification and follow up of highrisk pregnancies can also significantly contribute to prevent severe outcomes associated with the development of preeclampsia.

The International Hypertension Society (ISH) recognizes these gaps and encourages a wideranging discussion of key topics for advancing this field. In the 2021 edition of the ISH and
European Society of Hypertension (ESH) joint meeting, international leaders in the field of hypertension in pregnancy presented their most recent contributions in discovering new mechanisms involved in preeclampsia-related placental dysfunction and in the study of emerging biomarkers of preeclampsia.

The early onset of preeclampsia is mainly driven by abnormal trophoblast invasion and impaired arterial remodeling, leading to significant oxidative stress and exacerbated immune responses in the placenta. ${ }^{3-5}$ Dr. McClements has studied therapies using mesenchymal stem cells (MSC) originated from placentas of pregnancies with preeclampsia. 6,7 The potential of this cell therapy is justified by the fact that placentas are rich in MSC. These cells release extracellular vesicles (EV) containing mRNA, miRNAs and proteins that can alter different aspects of placentation, 